J Geriatr Oncol. 2014 July ; 5(3): 230-237. doi:10.1016/j.jgo.2014.02.001.

\title{
Hospital-based health care use correlates with incidence of adverse events among elderly Medicare patients treated in adjuvant chemotherapy trials (Alliance 70802) $\downarrow$
}

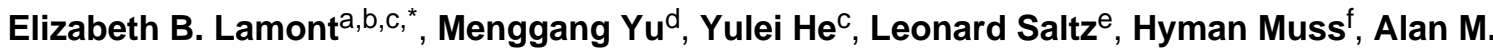 \\ Zaslavsky ${ }^{\mathrm{C}}$, and for the Alliance for Clinical Trials in Oncology \\ aMassachusetts General Hospital Cancer Center, Boston, MA, USA \\ bDepartment of Medicine, Harvard Medical School, Boston, MA, USA \\ 'Department of Health Care Policy, Harvard Medical School, Boston, MA, USA \\ dDepartment of Biostatistics and Medical Informatics, University of Wisconsin, Madison, WI USA \\ eDepartment of Medicine, Memorial Sloan Kettering Cancer Center, New York, NY, USA \\ fDepartment of Medicine, University of North Carolina, Chapel Hill, NC, USA
}

\begin{abstract}
Objective-Medicare claims can be useful in chemotherapy-related comparative effectiveness research (CER) estimating survival, but methods for estimating patients' treatment morbidity are currently lacking. We sought to determine if patients' health care use in the claims is a marker of treatment morbidity.

Materials and Methods-For 249 elderly Medicare patients with breast or colon cancer who were treated in two adjuvant clinical trials, we merged patients' National Cancer Institute Common Toxicity Criteria for Adverse Events (CTC AEs) trial data with their contemporaneous Medicare claims. We estimated associations of patients' grade $\geq 3$ CTC AE counts and their use of two types of hospital-based health care in claims (i.e., emergency room (ER) visits and hospitalizations).
\end{abstract}

\footnotetext{
${ }^{2}$ Financial support: The study was supported by grants from the National Cancer Institute: CA132900 (Lamont) and CA33601 (CALGB Statistics Center).

(C) 2014 Elsevier Ltd. All rights reserved.

"Corresponding author at: Department of Health Care Policy, Harvard Medical School, 180A Longwood Avenue, Boston, MA 02115, USA. Tel.: + 1617432 4465; fax: + 1617432 0173. lamont@ @cp.med.harvard.edu (E.B. Lamont).

Author Contributions

Concept and Design: E. Lamont, M. Yu, Y. He, A. Zaslafsky. Data Collection: E. Lamont, H. Muss, L. Saltz. Analysis and Interpretation of Data: E. Lamont, M. Yu, Y.

He, A. Zaslafsky, H. Muss, L. Saltz.

Manuscript Writing and Approval: E. Lamont, M. Yu, Y. He, A. Zaslafsky, H. Muss, L. Saltz.

Disclosures and Conflict of Interest Statements

The authors have no conflicts of interest to disclose.

Appendix A. Supplementary Data

Supplementary data to this article can be found online at http://dx.doi.org/10.1016/j.jgo.2014.02.001
} 
Results-ER visits and hospitalizations were significantly positively associated with grade $\geq 3$ CTC AE counts incurred by patients during the study. Eight percent of patients without any grade $\geq 3$ CTC AEs had one or more hospitalizations during the observation period compared to $43 \%$ of patients with three or more grade $\geq 3$ CTC AEs $(p<0.01)$. Those who were hospitalized at least once had more than three times the rate of grade $\geq 3$ CTC AEs (IRR 3.70, 95\% CI: 2.53-5.40) compared to those who were not. With each hospitalization, the daily incidence rate of any grade $\geq 3$ CTC AE more than doubled (IRR 2.10, 95\% CI: 1.54-2.86).

Conclusions-Because hospitalization is strongly associated with clinically significant toxicity it may be a useful outcome for Medicare claim-based CER comparing treatment morbidity for elderly patients receiving different adjuvant chemotherapy regimens.

\section{Keywords}

Elderly; Cancer; Medicare; Toxicity; Chemotherapy; Health care use; Comparative effectiveness research; Hospitalization; Adjuvant; Colon cancer; Breast cancer

\section{Introduction}

Medicare spends billions of dollars annually on chemotherapy for elderly patients with cancer, but surprisingly little is known about the extent to which cancer chemotherapies help or harm such elderly patients. ${ }^{1,2}$ This unsettling paradox is the direct result of the welldescribed under-enrollment of elderly patients with cancer in clinical trials of chemotherapy. ${ }^{3}-5$ The dearth of realistic estimates of chemotherapy-related survival and toxicities hinders community oncologists as they discuss with elderly patients the risks and benefits of chemotherapy use, compromising patient-physician decision-making. ${ }^{6,7}$

Population research using observational data sources for comparative effectiveness research (CER) has the potential to yield estimates of the benefits and risks of treatment for patients with cancer who are traditionally underrepresented in clinical trials. Overall survival is well measured in Medicare data, but post-treatment morbidity is not. Some researchers have posited that International Classification of Disease 9th Revision (ICD-9) diagnostic codes provide valid estimates of post-treatment toxicities affecting elderly usual care patients. ${ }^{8-15}$ Other research suggests that this is not the case; we found that Medicare ICD-9 diagnostic and procedure codes were poor measures of the common and clinically significant toxicities classified as grade $\geq 3$ Common Terminology Criteria for Adverse Events (CTC AEs), a gold-standard measure of toxicity. ${ }^{16}$ This finding motivated our search for alternative indicators of severe morbidity in elderly patients with cancer who are receiving chemotherapy (i.e., intercurrent morbidity) using Medicare data. Were reliable methods developed, such morbidity could be studied as a salient endpoint in Medicare-based CER.

We chose to study hospital-based health care use under Medicare because it is (1) a clinically meaningful measure of severity of illness (i.e., lesser illnesses can be treated in the outpatient setting), (2) something most elderly patients wish to avoid, ${ }^{17,18}$ (3) a risk factor for iatrogenic processes including life-threatening infections, ${ }^{19}$ (4) a risk factor for functional decline ${ }^{20}$ (5) easily measured in Medicare data, and (6) being used empirically in Medicare-based CER of adjuvant chemotherapy regimens as a measure of treatment-related 
toxicity. ${ }^{21}$ Specifically, we assess elderly Medicare patients treated on two adjuvant chemotherapy trials for breast and colon cancer and evaluate for associations between the burden of CTC AEs they incurred while in the clinical trials and the amount of hospitalbased health care they used during the same period. We hypothesized a positive association between standard clinical trial metrics of treatment toxicity and hospital-based health care use during the clinical trial period.

\section{Methods}

\subsection{Data and Cohorts}

2.1.1. CALGB Data-We used clinical trial data from the Cancer and Leukemia Group B (CALGB) to identify elderly clinical trial patients treated in the experimental setting with standard first-line adjuvant chemotherapy on CALGB breast and colon cancer trials (CALGB 49907 and 89803).22,23 The CALGB, now a part of the Alliance for Clinical Trials in Oncology, was an NCI-sponsored cooperative oncology research group representing a network of over 3000 physicians from 29 academic medical centers and 225 community hospitals. Members of multi-modality treatment programs in seven disease areas developed therapeutic trials, which were opened for patient accrual at CALGB institutions. Data from trials are maintained centrally. Registration variables common to all therapeutic trials include study number, subject identifiers, demographic and disease information, treatment information (e.g., drugs administered, dates of treatment, CTC AE information) and survival endpoints.

The CTC AE is the standard metric of chemotherapy-related toxicity used in clinical trials nationally. The taxonomy requires identification of a category of toxicity and within the category a numeric grade of severity of the toxicity, ranging from 1 (mild toxicity) to 5 (death). ${ }^{24}$ CTC AEs graded 3 or higher are considered clinically important and for this reason reports of clinical trial results usually include the proportion of patients with grade $\geq 3$ CTC AEs by type (e.g., neutropenia or diarrhea).

2.1.2. Medicare Data-Medicare is a federally sponsored health insurance program administered by the Centers for Medicare and Medicaid Services (CMS) whose beneficiaries include more than $96 \%$ of all US citizens aged 65 and older. ${ }^{25} \mathrm{CMS}$ maintains billing records of outpatient, inpatient, home health, hospice, durable medical equipment, and other claims for all beneficiaries not enrolled in risk contract health maintenance organizations (HMOs). Of note, Medicare reimburses providers for costs associated with clinical trials including those of drugs and drug combinations that have been previously established to be standards of care. All regimens we studied were standard chemotherapy regimens at the time of trial enrollment.

2.1.3. Cohort Construction-We identified all study subjects who enrolled in the standard arm of CALGB 49907 or either the standard or experimental arm of 89803.

CALGB 49907 studied women aged 65 and older with loco-regional breast cancer who were randomized to post-operative adjuvant chemotherapy with one of two standard chemotherapy regimens (i.e., the combination of doxorubicin and cyclophosphamide or the combination of cyclophosphamide, methotrexate, and fluorouracil) vs. the experimental arm 
(i.e., oral capecitabine). We study only patients treated on the standard arm as capecitabine is not reliably measured in claims. ${ }^{22}$ CALGB 89803 studied patients with loco-regional colon cancer who were randomized to post-operative adjuvant chemotherapy with standard fluorouracil and leucovorin vs. fluorouracil, leucovorin, and irinotecan. ${ }^{23}$ The Appendix (page 2) contains a detailed description of patient eligibility for each trial. For the 479 CALGB patients who were (1) Medicare eligible based on age and (2) treated at centers that were reimbursed by Medicare, we were able to match 406 (85\%) to CMS Medicare claims files from the corresponding calendar period using Social Security numbers. The linked data set contained both CALGB clinical trial data (e.g., demographic information, study arm, and CTC AE information) and Medicare data. Elderly CALGB patients who did not match to Medicare data were more likely to have been treated in the breast trial and be female (see Appendix page 3). Among the 406 patients, 98 were excluded because they were enrolled in HMOs for which claims data are unavailable. Patients enrolled in HMOs were more likely to be male, treated in the colon trial, and be younger than patients not enrolled in HMOs (see Appendix, page 4). An additional 46 patients were excluded because they were not continuously eligible for Medicare parts A and B during the observation period. Under both the latter conditions, patients' health care use may be incompletely observed leading to biased estimates of hospital-based health care use. We excluded 13 patients because of incomplete information regarding the observation period. The final analytic sample consisted of 249 elderly Medicare patients treated in one of the two CALGB adjuvant chemotherapy trials. We chose to study patients with breast or colorectal cancer who were receiving adjuvant chemotherapy because these patients might reasonably be expected to use hospital-based health care during the clinical trial for chemotherapy-related toxicity management. That is, to be eligible for treatment in the trial, the patients had to have fully recovered from their curative-intent cancer surgery; this implied that their gross tumor had been removed, leaving only microscopic disease. For patients with micro-metastatic disease who are receiving adjuvant chemotherapy, hospitalizations would be expected to more often be chemotherapy-related toxicity rather than primarily related to their tumor (e.g., postoperative complications and/or progressive cancer).

The observation period was patient-specific and bounded (inclusively) by the date of first treatment with clinical trial therapy through 30 days following the date of last treatment with the same therapy, as ascertained from Medicare claims.

2.1.4. Outcome Variables-The key outcome variable was the number of grade $\geq 3$ CTC AEs experienced by each patient during the observation period. Patient demographic and disease attributes were obtained from CALGB and CMS data.

2.1.5. Predictor Variables-The key predictor variables came from the MEDPAR file and were counts of the following types of hospital-based health care utilization incurred during the study period: ER visits, hospitalizations, and days in hospital. The former two variables were also transformed into binary variables indicating at least one incident of each type. If patients were admitted to the hospital through the ER, we counted only the hospitalization. Thus ER visits were necessarily self-limited hospital-based health care encounters. Covariates were patient age, sex, race, Eastern Cooperative Oncology Group 
(ECOG) performance status (PS), Charlson comorbidity score (CCS) and neighborhood poverty. Additionally, we adjusted for the season during which treatment was initiated (i.e., winter, spring, summer, or fall).

2.1.6. Statistical Analyses-To assess the hypothesis that hospital-based health care use might function as an indicator of toxicities in subsequent CER, we modeled AEs as the outcomes of interest and hospital-based health care use as the predictors. We tested associations between covariates and outcomes using chi-square tests for categorical predictors and t-tests for continuous variables. For each treatment arm, we also described the association between number of hospital-based events and number of AEs with Spearman correlation coefficients. We described multivariate associations between counts of patient grade $\geq 3$ CTC AEs and use of any of the two types of hospital-based health care studied with negative binomial log-linear regressions. Negative binomial log-linear regression also described multivariate associations between count of patient grade 23 CTC AEs and episodes of the two types of hospital-based health care incurred during the study period as well as days in hospital. Because time on treatment for clinical trials was not uniform across patients, we adjusted the models for the observation period. The observation period was patient-specific and bounded (inclusively) by the date of first treatment with clinical trial therapy through 30 days following the date of last treatment with the same therapy. The natural $\log$ of this number was included as a predictor to account for non-uniformity of the observation period. Additionally, because patients were treated at a fixed number of treating facilities, we adjusted the standard errors of the estimates for the clustering of multiple patients within single treating facilities.

Finally, in an additional set of analyses, we studied the patients treated in the adjuvant colon cancer trial (i.e., CALGB 89803), to determine whether covariates modified the association between hospitalization and the incidence rate of AEs. We tested interactions of each covariate with hospitalization. These included the treatment arm to which the patients were randomized as well as by other salient patient attributes including demographics, area poverty, and seasonality. To do this, we investigated separate models that included hospitalization and patient attribute interaction terms. In compliance with our data use agreement with Medicare, we have suppressed those results where Medicare variables have cell sizes $<11$. This research was approved by Duke University's, Harvard Medical School's, and Massachusetts General Hospital's institutional review boards and conducted in compliance with their regulations.

\section{Results}

The cohorts' characteristics and hospital-based health care utilization are described in Table 1. More than $50 \%$ of patients experienced at least one clinically significant toxicity (i.e., CTC AE grade 23) but none experienced grade 5 toxicity (i.e., death). For patients with at least one CTC AE grade $\geq 3$, the median numbers of distinct toxicity categories and events were both 2. Table 2 contains results of bivariate analyses of predictor and outcome variables. Patients who were treated in the colon cancer trials, those with higher ECOG scores (indicating poorer performance status), greater comorbid illness, who lived in areas with increased poverty, and any grade $\geq 3$ CTC AEs were all more likely than others to be 
hospitalized during the trial. There was a positive association between the number of episodes grade $\geq 3$ CTC AEs and each of the three types of hospital-based health care use we studied (i.e., ER use, hospitalizations, and hospital days). For example, $8 \%$ of patients without any grade $\geq 3$ CTC AEs had at least one hospital admission during the observation period compared to $43 \%$ of patients with three or more grade $\geq 3$ CTC AEs ( $p<0.01)$. Fig. 1 shows the monotonically increasing relationship of the number of ER visits, hospitalizations, and days in hospital with counts of grade $\geq 3$ CTC AEs ranging from none to three or more. Table 3 describes the correlation between the number of grade $\geq 3$ CTC AEs that patients experienced and the amount of each type of hospital-based health care they used during the study. Hospitalization and hospital days appear to be more strongly correlated with patient toxicity than ER visits. Table 4 contains results of adjusted negative binomial log-linear regressions, showing positive clinically and statistically significant associations between the number of patients' grade $\geq 3$ CTC AEs incurred and the amount of each of the two types of hospital-based care they used (i.e., ER visits and hospitalizations) as well as the number of days in hospital. In these results, again, the coefficients on the variables indicating hospitalization (rather than ER visits) are more strongly associated with toxicity, though 95\% confidence intervals do overlap for ER visits and hospitalizations. For example with each hospitalization, patients' daily incidence rate of grade $\geq 3$ CTC AEs doubled (incidence ratio rate [IRR] 2.10, 95\% CI: 1.54-2.86) while adjusting for age, sex, race, comorbidity, ECOG PS, tumor site, neighborhood poverty, and season of the year. As shown in Table 5, those patients who were hospitalized at least once had nearly four times the rate of grade $\geq 3$ CTC AEs (IRR 3.70, 95\% CI: 2.53-5.40) compared to those who were not. Table 5 contains results of adjusted negative binomial log-linear regressions, showing positive clinically and statistically significant associations between the number of patients' grade $\geq 3$ CTC AEs incurred and at least one patient hospitalization during the study period. In these results, the daily incident rate for CTC AEs $\geq 3$ increased by 3.70 (95\% CI: 2.53-5.40) for patients who experienced at least one hospitalization during the study period. Adjusted incidence of toxicity was lower on the adjuvant colon trial than in the adjuvant breast cancer trial (IRR 0.54, 95\% CI: 0.35-0.81) and adjusted incidence of toxicity was higher for those treated in the summer relative to the winter season (IRR 2.72, 95\% CI: 1.66-4.46). Table 6 contains the results of a subset analysis through which we evaluated whether there was a treatment arm by hospitalization interaction associated with toxicity for patients treated in the colon cancer trial. Those patients who were hospitalized at least once had more than seven times the rate of grade $\geq 3$ CTC AEs (IRR 7.10, 95\% CI: 4.12-12.22) compared to those who were not. The estimated covariate effects are generally consistent with those in Table 5.

\section{Discussion}

For elderly Medicare beneficiaries with breast or colon cancer who were treated in two adjuvant chemotherapy trials, gold-standard clinical trial measures of toxicity were strongly associated with hospital-based health care utilization during the treatment period, with hospitalization itself potentially the strongest predictor. This suggests that hospitalizations documented in Medicare claims may be markers of intercurrent treatment toxicity in the adjuvant chemotherapy setting for elderly patients with breast or colon cancer. These results are important for at least three reasons. First, these findings may accelerate CER directed at 
estimating the risks as well as benefits of specific chemotherapy agents in the elderly through identification of a clinically salient morbidity endpoint, hospitalization, that is easily measured through the population-based CMS data. The additional information may be of importance to patients and physicians choosing among chemotherapy regimens. Second, these findings may be useful to health policy makers concerned about hospitalizations, the single largest component of Medicare spending for elderly patients with cancer. ${ }^{26}$ Third, measurement of post-treatment health care burden may provide insight as to the generalizability of toxicity estimates that emanate from practice-shaping clinical trials in which the elderly are often under-represented.

Among the limitations to our work are concerns regarding generalizability of our approach to observational CER. Applying methods used in clinical trials to the observational setting can be analytically challenging because, unlike the trial patients we studied, patients in the usual care setting (i.e., observational setting) are not randomized to their treatments so that both observable and unobservable features related to patients, providers, and other sources may confound apparent associations between treatments and outcomes. For example, in the clinical trial breast cohort, though patients' age was representative of usual care patients treated in the community, patients were on average slightly older than the usual care setting, never male, and the percentage of white patients was higher than in the usual care setting. ${ }^{27,28}$ In the clinical trial colon cancer cohort, patients were on average two years younger than in the usual care setting and more often men, but the percentage of white patients was similar to the usual care setting. ${ }^{29}$ These findings underscore the fact that our results are applicable to trial-eligible recipients of adjuvant chemotherapy age 65 or older and then only while they are receiving treatment through 30 days afterward.

Fortunately, concerns about confounding in the study of observational data and associated CER are not new. In fact, they have led over thirty years to the genesis of rigorous analytic methods intended to attenuate confounding in CER, acknowledging that it is not always feasible or ethical to undertake randomized controlled trials yet information regarding expected outcomes of therapies is needed by decision-makers (e.g., patients, their physicians). ${ }^{30-35}$

In conclusion, hospital-based health care use may be a useful outcome in CER intended to estimate differences in the risk of morbidity of specific treatments rendered in the usual care setting. Among the types of hospital-based health care use studied, hospitalization itself had the strongest association with the clinical trial toxicity measure and thus may be a salient outcome for CER that seeks to compare the post-treatment morbidity of specific adjuvant chemotherapy regimens.

\section{Supplementary Material}

Refer to Web version on PubMed Central for supplementary material.

\section{REFERENCES}

1. Warren JL, Yabroff KR, Meekins A, Topor M, Lamont EB, Brown ML. Evaluation of trends in the cost of initial cancer treatment. J Natl Cancer Inst. 2008; 100(12):888-897. [PubMed: 18544740] 
2. Yabroff KR, Lamont EB, Mariotto A, Warren JL, Topor M, Meekins A, et al. Cost of care for elderly cancer patients in the United States. J Natl Cancer Inst. 2008; 100:630-641. [PubMed: 18445825]

3. Hutchins LF, Unger JM, Crowley JJ, Coltman CA Jr, Albain KS. Underrepresentation of patients 65 years of age or older in cancer-treatment trials. N Engl J Med. 1999; 341(27):2061-2067. [PubMed: 10615079]

4. Murthy VH, Krumholz HM, Gross CP. Participation in cancer clinical trials: race-, sex-, and agebased disparities. JAMA. 2004; 291(22):2720-2726. [PubMed: 15187053]

5. Gross CP, Wong N, Dubin JA, Mayne ST, Krumholz HM. Enrollment of older persons in cancer trials after the medicare reimbursement policy change. Arch Intern Med. 2005; 165(13):1514-1520. [PubMed: 16009867]

6. Hersham D, Calhoun E, Zapert K, Wade S, Malin J, Barron R. Patients' perceptions of physicianpatient discussions and adverse events with cancer therapy. Arch Drug Inf. 2008; 1(2):70-78. [PubMed: 19639029]

7. Dale DC. Poor prognosis in elderly patients: the role of bias and under treatment. J Support Oncol. 2003; 1(14 Suppl 2):11-17. [PubMed: 15346995]

8. Du SL, Osborne C, Goodwin JS. Population-based assessment of hospitalizations for toxicity from chemotherapy in older women with breast cancer. J Clin Oncol. 2002; 20:4636-4642. [PubMed: 12488407]

9. Chen-Hardee S, Chrischilles EA, Voelker MD, Brooks JM, Scott S, Link BK, et al. Populationbased assessment of hospitalizations for neutropenia from chemotherapy in older adults with nonHodgkins lymphoma (United States). Cancer Causes Control. 2006; 17:647-654. [PubMed: 16633911]

10. Du XL, Chan W, Giordano S, Geraci JM, Delclos GL, Burau K, et al. Variation in modes of chemotherapy administration for breast carcinoma and association with hospitalization for chemotherapy-related toxicity. Cancer. 2005; 104:913-924. [PubMed: 15991239]

11. Polednak AP. Surveillance for hospitalizations with infection-related diagnoses after chemotherapy among breast cancer patients diagnosed before age 65. Chemotherapy. 2004; 50(4):157-161. [PubMed: 15347907]

12. Hassett MJ, O'Malley AJ, Pakes JR, Newhouse JP, Earle CC. Frequency and cost of chemotherapy-related serious adverse effects in a population sample of women with breast cancer. J Natl Cancer Inst. 2006; 98(16):1108-1117. [PubMed: 16912263]

13. Silber JH, Rosenbaum PR, Polsky D, Ross RN, Even-Shoshan O, Schwartz JS, et al. Does ovarian cancer treatment and survival differ by the specialty providing chemotherapy? J Clin Oncol. 2007; 25(10):1169-1175. [PubMed: 17401005]

14. Delea TE, Vera-Llonch M, Edelsberg JS, McGarry L, Anton S, Ulcickas-Yood M, et al. The incidence and cost of hospitalization for 5FU toxicity among Medicare beneficiaries with metastatic colorectal cancer. Value Health. 2002; 5(1):35-43. [PubMed: 11873382]

15. Schrag D, Cramer LD, Bach PB, Begg CB. Age and adjuvant chemotherapy use after surgery for stage III colon cancer. J Natl Cancer Inst. 2001; 93(11):850-857. [PubMed: 11390534]

16. Lamont EB, Herndon JE, Weeks JC, Henderson IC, Lilenbaum R, Schilsky RL, et al. Measuring clinically significant chemotherapy-related toxicities using Medicare claims from cancer and leukemia group B (CALGB) trial participants. Med Care. 2008; 46(3):303-308. [PubMed: 18388845]

17. Steinhauser KE, Christakis NA, Clip NC, McNeilly M, McIntyre L, Tulsky JA. Factors considered important at the end of life by patients, family, physicians and other care providers. JAMA. 2000; 284(19):2476-2482. [PubMed: 11074777]

18. Fried TR, van Doorn C, Tinetti ME, Drickamer MA. Older persons' preferences for site of treatment in acute illness. J Gen Intern Med. 1998; 13:522-527. [PubMed: 9734788]

19. Klevens RM, Edwards JR, Richards CL, Horan TC, Gaynes RP, Pollock DA, et al. Estimating health care-associated infections and deaths in U.S. hospitals, 2002. Public Health Rep. 2007; 122:160-166. [PubMed: 17357358] 
20. Kelley AS, Ettner SL, Morrison RS, Du Q, Sarkisian CA. Disability and decline in physical function associated with hospital use at the end of life. J Gen Intern Med. 2012; 27(7):794-800. [PubMed: 22382455]

21. Sanoff HK, Carpenter WR, Freburger J, Li L, Chen K, Zullig LL, et al. Comparison of adverse events during 5-fluorouracil versus 5-fluorourcail/Oxaliplatin adjuvant chemotherapy for stage III colon cancer. Cancer. 2012; 118:4309-4320. [PubMed: 22294436]

22. Muss HB, Berry DA, Cirrincione CT, Theodoulou M, Mauer AM, Kornblith AB, et al. CALGB Investigators. Adjuvant chemotherapy in older women with early-stage breast cancer. N Engl J Med. 2009; 360(20):2055-2065. [PubMed: 19439741]

23. Saltz LB, Niedzwicki D, Hollis D, Goldberg RM, Hantel A, Thomas JP, et al. Irinotecan fluorouracil plus leucovorin is not superior to fluorouracil plus leucovorin alone as adjuvant treatment for stage III colon cancer: results of CALGB 89803. J Clin Oncol. 2007; 25(23):34563461. [PubMed: 17687149]

24. National Cancer Institute. [Accessed October 14, 2012] Common terminology criteria for adverse events: index. Available at, http://ctep.cancer.gov/forms/CTCAE_Index.pdf

25. Hatten J. Medicare's common denominator: the covered population. Health Care Finance Rev. 1980:53-64.

26. Yabroff KR, Lamont EB, Mariotto A, Warren JL, Topor M, Meekins A, et al. Cost of care for elderly cancer patients in the United States. J Natl Cancer Inst. 2008; 100:630-641. [PubMed: 18445825]

27. Wheeler SB, Carpenter WR, Peppercorn J, Schenck AP, Weinberger M, Biddle AK. Predictors of timing of adjuvant chemotherapy in older women with hormone receptor-negative, stages II-III breast cancer. Breast Cancer Res Treat. 2012; 131:207-216. [PubMed: 21842244]

28. Elkin EB, Hurria A, Mitra N, Schrag D, Panageas K. Adjuvant chemotherapy and survival in older women with hormone receptor-negative breast cancer. J Clin Oncol. 2006; 24:2757-2764. [PubMed: 16782916]

29. Lamont EB, Lauderdale DS, Schilsky RL, Christakis NA. Construct validity of Medicare chemotherapy claims: the case of 5FU. Med Care. 2002; 40(3):201-211. [PubMed: 11880793]

30. Sox HC, Goodman SN. The methods of comparative effectiveness research. Annu Rev Public Health. 2012; 33:425-445. [PubMed: 22224891]

31. Armstrong K. Methods in comparative effectiveness research. J Clin Oncol. 2012; 30(34):42084214. [PubMed: 23071240]

32. Rubin DB. Estimating causal effects from large data sets using propensity scores. Ann Intern Med. 1998; 127(8S):757-763. [PubMed: 9382394]

33. Rubin DB. Using multivariate matched sampling and regression adjustment to control bias in observational studies. J Am Stat Assoc. 1979; 74:318-328.

34. Rosenbaum PR, Rubin DB. The bias due to incomplete matching. Biometrics. 1985; 41(1):103116. [PubMed: 4005368]

35. Rosenbaum PR, Rubin DB. The central role of the propensity score in observational studies for causal effects. Biometrika. 1984; 70:41-55. 


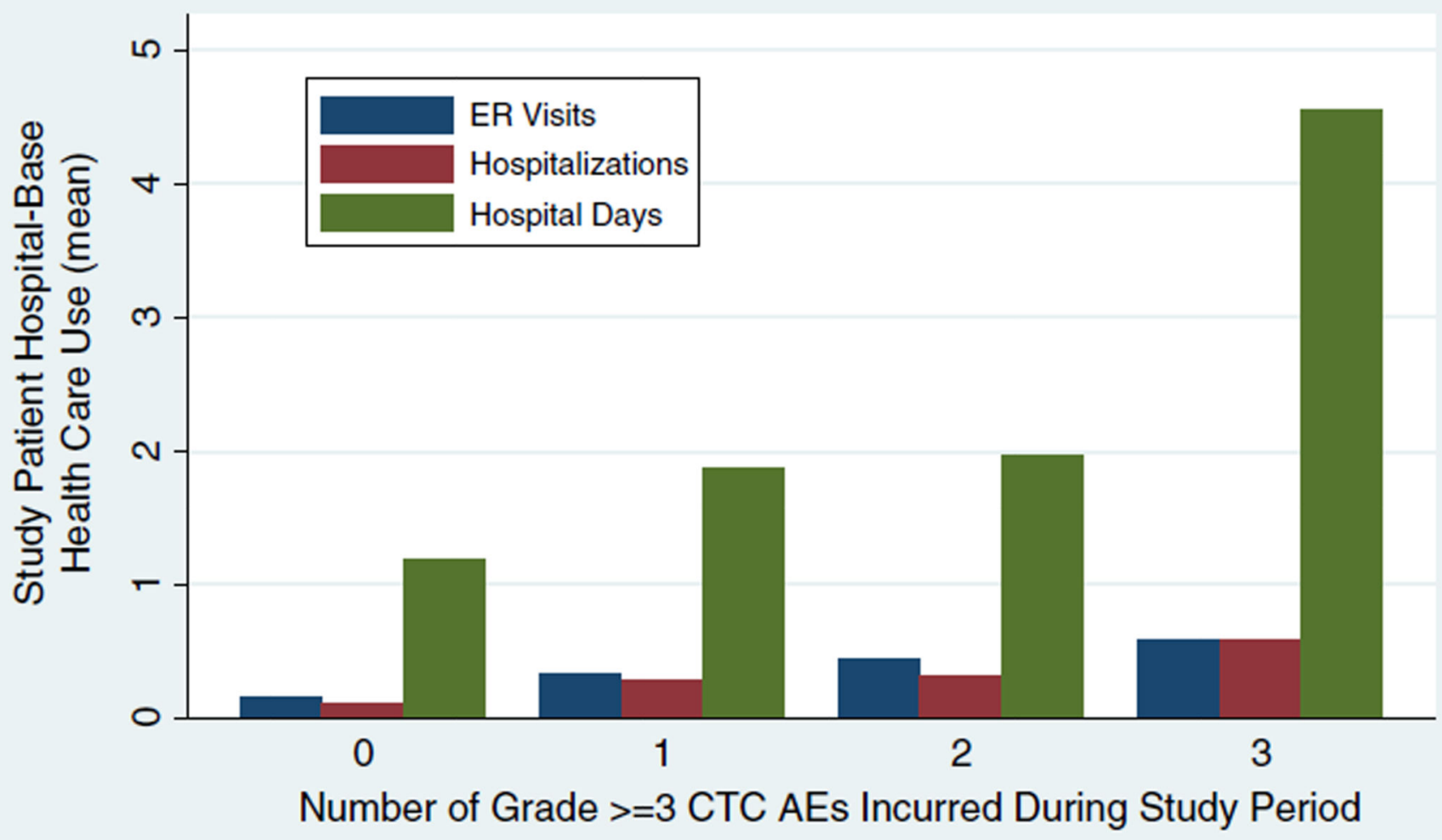

Legend: Bar graph showing monotonically increasing relationship of the number of ER visits, hospitalizations, and days in hospital with counts of grade $\geq 3$ CTC AEs ranging from none to three or more. ER= Emergency Room; CTC AEs= Common Toxicity Criteria for Adverse Events.

Fig. 1.

Trial patients' use of hospital-based health care by grade $\geq 3$ CTCAE treatment burden. Legend: Bar graph showing monotonically increasing relationship of the number of ER visits, hospitalizations, and days in hospital with counts of grade 3 CTC AEs ranging from none to three or more. ER = emergency room; CTC AEs = Common Toxicity Criteria for Adverse Events. 


\section{Table 1}

Attributes of elderly medicare patients treated on two CALGB adjuvant chemotherapy trials and their intercurrent hospital-based health care use $(\mathrm{N}=249)$.

\begin{tabular}{|c|c|c|c|}
\hline & $\begin{array}{c}\text { Breast cancer } \\
\text { cohort } \\
(\mathbf{n}=\mathbf{1 5 9})\end{array}$ & $\begin{array}{c}\text { CRC cancer } \\
\text { cohort } \\
(\mathbf{n}=90)\end{array}$ & $\begin{array}{c}\text { Total } \\
(\mathbf{N}=\mathbf{2 4 9})\end{array}$ \\
\hline \multicolumn{4}{|l|}{ Age } \\
\hline $65-69$ & $25 \%$ & $36 \%$ & $29 \%$ \\
\hline $70-74$ & $40 \%$ & $39 \%$ & $39 \%$ \\
\hline$>75$ & $35 \%$ & $25 \%$ & $32 \%$ \\
\hline \multicolumn{4}{|l|}{ Sex } \\
\hline Female & $100.0 \%$ & $39 \%$ & $78 \%$ \\
\hline Male & $00.0 \%$ & $61 \%$ & $22 \%$ \\
\hline \multicolumn{4}{|l|}{ Race } \\
\hline White & $88 \%$ & $92 \%$ & $89 \%$ \\
\hline Black & NR & NR & NR \\
\hline Other & NR & NR & NR \\
\hline \multicolumn{4}{|l|}{ ECOG PS } \\
\hline 0 & $73 \%$ & $64 \%$ & $70 \%$ \\
\hline 1 & $26 \%$ & $34 \%$ & $29 \%$ \\
\hline 2 & $1 \%$ & $2 \%$ & $1 \%$ \\
\hline Mean Charlson Comorbidity Score (range) & $0.86(0-4)$ & $0.62(0-4)$ & $0.77(0-4)$ \\
\hline $\begin{array}{l}\text { Mean area poverty (\% of residents in ZIP whose incomes are <federal poverty level) } \\
\text { Season of the year treatment started }\end{array}$ & $10.5 \%$ & $10.2 \%$ & $10.4 \%$ \\
\hline Winter & $28 \%$ & $29 \%$ & $28 \%$ \\
\hline Spring & $26 \%$ & $27 \%$ & $26 \%$ \\
\hline Summer & $21 \%$ & $20 \%$ & $21 \%$ \\
\hline Fall & $25 \%$ & $24 \%$ & $25 \%$ \\
\hline Days on treatment +30 days (median and range) & $95(30-212)$ & $222(30-338)$ & 171 \\
\hline Any grade $\geq 3 \mathrm{CTC} \mathrm{AE}$ & $66 \%$ & $64 \%$ & $65 \%$ \\
\hline Count of episodes of $\geq 3 \mathrm{CTC} \mathrm{AE}$ (median and range) & $2(0-14)$ & $1(0-10)$ & $1(0-14)$ \\
\hline $\begin{array}{l}\text { Count of distinct categories of } \geq 3 \mathrm{CTC} \mathrm{AE} \text { (median and range) } \\
\text { Any of the following: }\end{array}$ & $1(0-11)$ & $1(0-10)$ & $1(0-11)$ \\
\hline ER use & $26 \%$ & $26 \%$ & $26 \%$ \\
\hline Hospitalization & $20 \%$ & $33 \%$ & $25 \%$ \\
\hline \multicolumn{4}{|l|}{ Median episodes/patient of hospital-based health care use (range) } \\
\hline ER use & $0(0-3)$ & $0(0-4)$ & $0(0-4)$ \\
\hline Hospitalization & $0(0-2)$ & $0(0-6)$ & $0(0-6)$ \\
\hline Hospital days & $0(0-56)$ & $0(0-48)$ & $0(0-56)$ \\
\hline
\end{tabular}

Legend: ECOG PS = Eastern Cooperative Oncology Group performance status; CTC AE = Common Toxicity Criteria for Adverse Events; ER = emergency room; $\mathrm{NR}=$ not reported as cell size too small. 


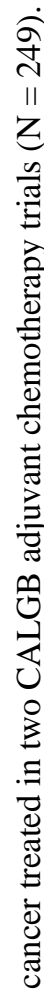

N

응

胥

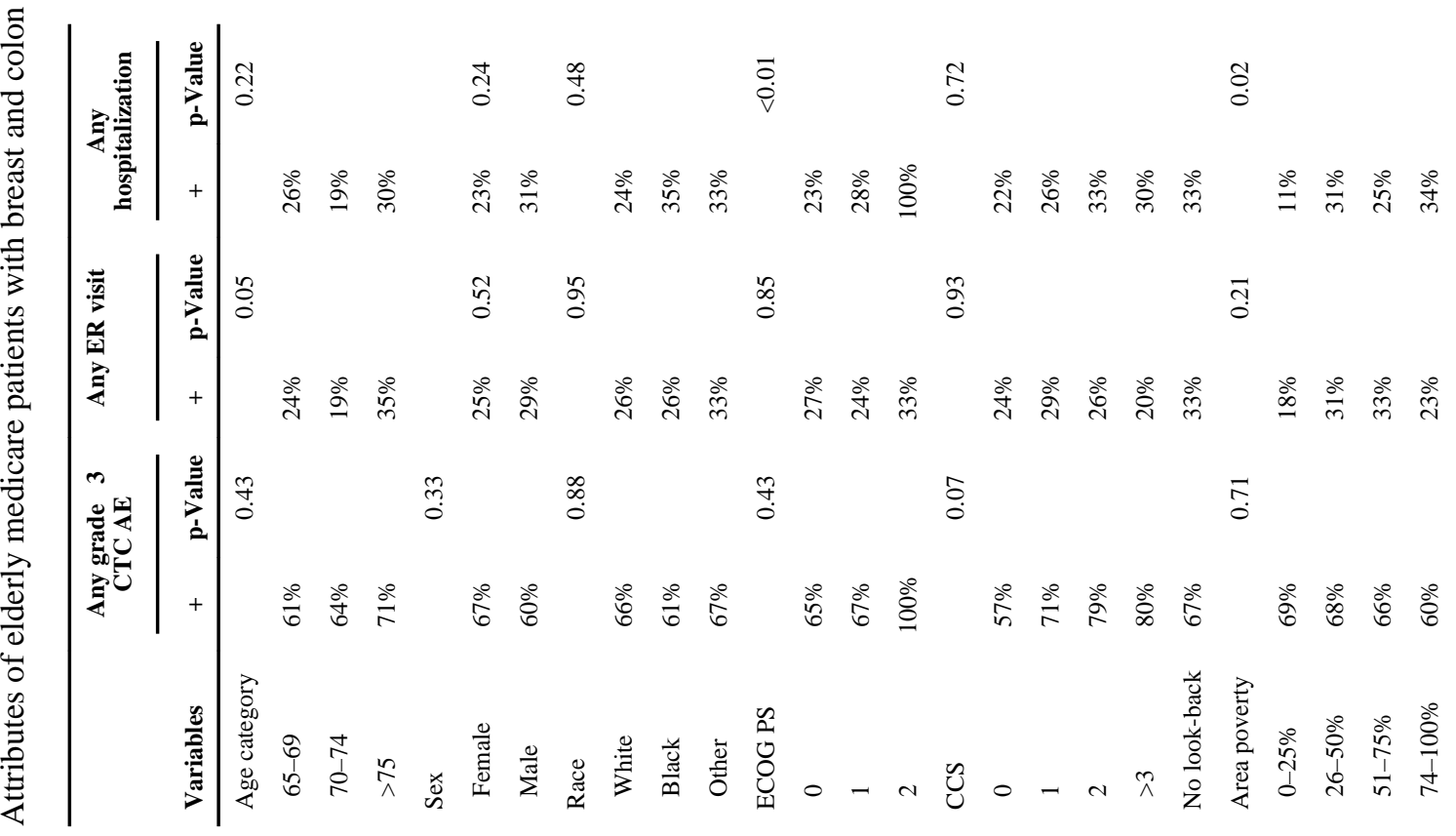

J Geriatr Oncol. Author manuscript; available in PMC 2015 July 01. 


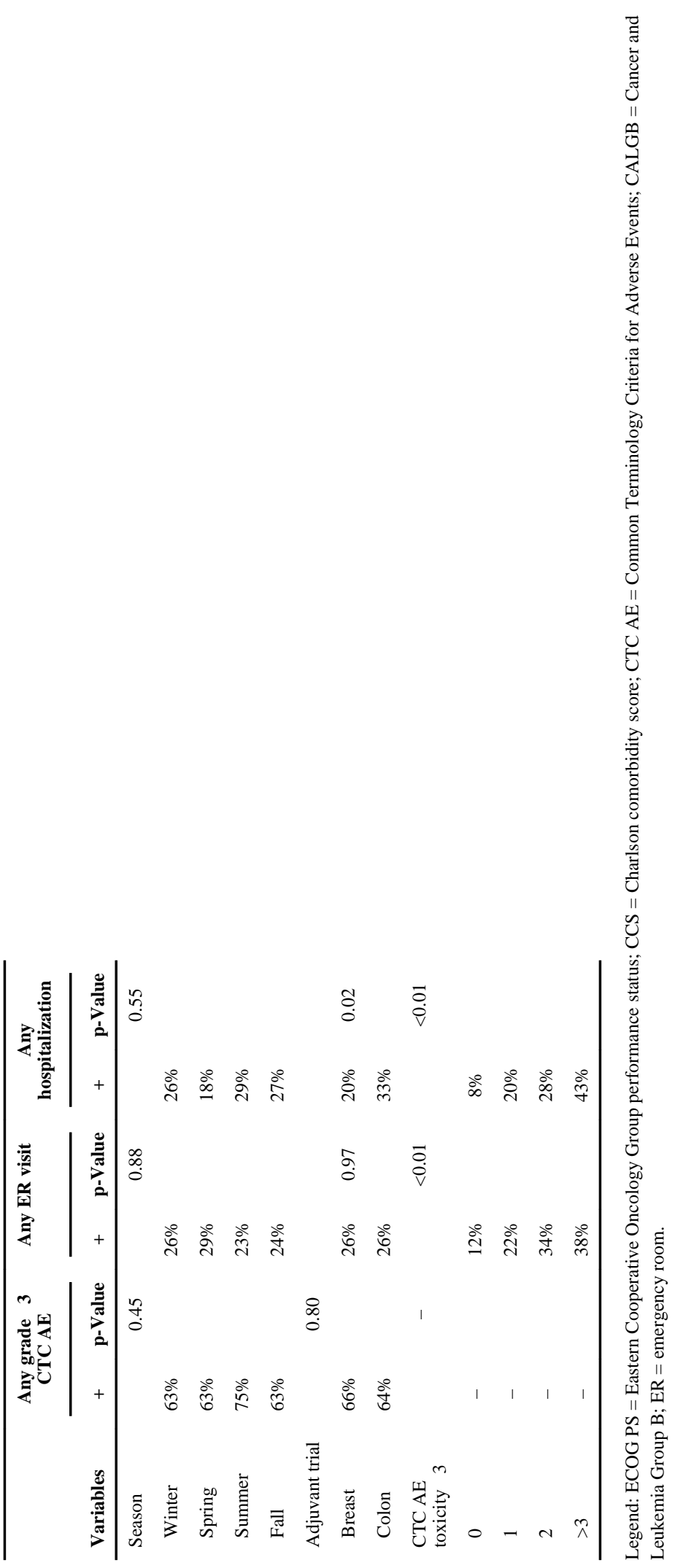

J Geriatr Oncol. Author manuscript; available in PMC 2015 July 01. 
Table 3

Correlation between trial patient-level count of grade $\geq 3$ CTC AEs and their hospital-based health care use during clinical trial $(\mathrm{N}=249)$.

\begin{tabular}{ccc}
\hline $\begin{array}{c}\text { Hospital-based } \\
\text { health care }\end{array}$ & $\begin{array}{c}\text { Spearman } \\
\text { correlation (rho) }\end{array}$ & p-Value \\
\hline ER visits & 0.27 & $<0.01$ \\
Hospitalizations & 0.35 & $<0.01$ \\
Hospital days & 0.34 & $<0.01$ \\
\hline
\end{tabular}

Legend: CTC AE = Common Terminology Criteria for Adverse Events; ER = emergency room. 


\section{Table 4}

Results of adjusted negative binomial log-linear regression models quantifying associations between number of episodes of hospital-based health care and counts of grade $\geq 3$ CTC AEs incurred by patients during the study period $(\mathrm{N}=249)$.

\begin{tabular}{lcc}
\hline \multicolumn{1}{c}{ Variables } & IRR & 95\% CI \\
\hline Amount of hospital-based health care & & \\
Number of ER visits & 1.61 & $1.32-1.96$ \\
Number of hospitalizations & 2.10 & $1.54-2.86$ \\
Number of days in hospital & 1.08 & $1.04-1.12$ \\
\hline
\end{tabular}

Legend: This table contains the results of negative binomial log-linear regressions measuring associations, at the patient-level, of episodes of grade $\geq 3$ toxicities and episodes of hospital-based health care use during study period (i.e., date of first trial therapy through 30 days following last trial therapy). The IRR is daily incidence rate ratio for grade $>3$ toxicity corresponding to a one unit increase in the specific type of health care use. The analyses account for variation in the length of the number of days that the patients were observed and adjust standard errors to account for clustering of patients within treatment centers. IRR $=$ incidence rate ratio; $\mathrm{CI}=$ confidence interval.

Results are adjusted for patient age, sex, race, tumor site, Eastern Cooperative Oncology Group performance status, comorbidity, area poverty, and seasonality. 


\section{Table 5}

Results of adjusted negative binomial log-linear regression models quantifying associations between hospitalizations and grade 23 CTC AEs during the study period $(\mathrm{N}=249)$.

\begin{tabular}{|c|c|c|}
\hline Variables & IRR & $95 \% \mathrm{CI}$ \\
\hline Any hospitalization & 3.70 & $2.53-5.40$ \\
\hline \multicolumn{3}{|l|}{ Adjuvant trial } \\
\hline Breast & 1.00 & Referent \\
\hline Colon & 0.54 & $0.35-0.81$ \\
\hline \multicolumn{3}{|l|}{ Age category } \\
\hline $65-69$ & 1.00 & Referent \\
\hline $70-74$ & 1.22 & $0.80-1.86$ \\
\hline$>75$ & 1.39 & $0.90-2.14$ \\
\hline \multicolumn{3}{|l|}{ Sex } \\
\hline Female & 1.00 & Referent \\
\hline Male & 0.65 & $0.39-1.07$ \\
\hline \multicolumn{3}{|l|}{ Race } \\
\hline White & 1.00 & Referent \\
\hline Black & 0.90 & $0.49-1.65$ \\
\hline Other & 1.15 & $0.71-1.87$ \\
\hline CS & 1.09 & $0.90-1.33$ \\
\hline \multicolumn{3}{|l|}{ ECOG PS } \\
\hline 0 & 1.00 & Referent \\
\hline 1 & 1.20 & $0.78-1.85$ \\
\hline 2 & 0.62 & $0.24-1.58$ \\
\hline \multicolumn{3}{|l|}{ ZIP poverty } \\
\hline $0-25 \%$ & 1.00 & Referent \\
\hline $26-50 \%$ & 0.73 & $0.46-1.16$ \\
\hline $51-75 \%$ & 1.06 & $0.65-1.75$ \\
\hline $74-100 \%$ & 0.87 & $0.47-1.62$ \\
\hline \multicolumn{3}{|l|}{ Season } \\
\hline Winter & 1.00 & Referent \\
\hline Spring & 1.33 & $0.85-2.08$ \\
\hline Summer & 2.72 & $1.66-4.46$ \\
\hline Fall & 1.43 & $0.90-2.28$ \\
\hline
\end{tabular}

Legend: This table contains the results of negative binomial log-linear regressions expressing the rate of study patients experiencing a grade 3 toxicity during study period (i.e., date of first trial therapy through 30 days following last trial therapy) if they have at least one hospitalization during the study period. The IRR is daily incidence rate ratio for grade $>3$ toxicity. The analyses account for variation in the length of the number of days that the patients were observed and adjust standard errors to account for clustering of patients within treatment centers. IRR $=$ incidence rate ratio; $\mathrm{CI}=$ confidence interval. 


\section{Table 6}

Results of adjusted negative binomial log-linear regression models evaluating for treatment arm by hospitalization interaction and incidence rate of grade $\geq 3$ CTC AEs incurred by patients with colon cancer during the study period $(\mathrm{N}=90)$.

\begin{tabular}{|c|c|c|}
\hline Variables & IRR & $95 \%$ CI \\
\hline Any hospitalization & 7.10 & $4.12-12.22$ \\
\hline 5FU/LV (control arm) & 0.57 & $0.30-1.08$ \\
\hline Any hospitalization $\times 5 \mathrm{FU} / \mathrm{LV}($ control arm) & 0.72 & $0.33-1.59$ \\
\hline \multicolumn{3}{|l|}{ Age category } \\
\hline $65-69$ & 1.00 & Referent \\
\hline $70-74$ & 1.24 & $0.55-2.78$ \\
\hline$>75$ & 2.43 & $1.26-4.69$ \\
\hline \multicolumn{3}{|l|}{ Sex } \\
\hline Female & 1.00 & Referent \\
\hline Male & 0.33 & $0.16-0.68$ \\
\hline \multicolumn{3}{|l|}{ Race } \\
\hline White & 1.00 & Referent \\
\hline Black & 0.47 & $0.09-2.36$ \\
\hline Other & 2.40 & $0.93-6.15$ \\
\hline $\mathrm{CS}$ & 1.61 & $1.13-2.33$ \\
\hline \multicolumn{3}{|l|}{ ECOG PS } \\
\hline 0 & 1.00 & Referent \\
\hline 1 & 1.69 & $0.88-3.23$ \\
\hline 2 & 0.12 & $0.03-0.44$ \\
\hline \multicolumn{3}{|l|}{ ZIP poverty } \\
\hline $0-25 \%$ & 1.00 & Referent \\
\hline $26-50 \%$ & 0.62 & $0.26-1.48$ \\
\hline $51-75 \%$ & 0.65 & $0.30-1.37$ \\
\hline $74-100 \%$ & 0.27 & $0.11-0.64$ \\
\hline \multicolumn{3}{|l|}{ Season } \\
\hline Winter & 1.00 & Referent \\
\hline Spring & 1.92 & $1.04-3.53$ \\
\hline Summer & 2.48 & $1.30-4.74$ \\
\hline Fall & 1.88 & $1.12-3.16$ \\
\hline
\end{tabular}

Legend: This table contains the results of negative binomial log-linear regressions measuring associations, at the patient-level, of episodes of grade $\geq 3$ toxicities and episodes of hospital-based health care use during study period (i.e., date of first trial therapy through 30 days following last trial therapy). The IRR is daily incidence rate ratio for grade $>3$ toxicity. The analyses account for variation in the length of the number of days the patients were observed and adjust standard errors to account for clustering of patients within treatment centers. IRR $=$ incidence rate ratio; $\mathrm{CI}=$ confidence interval. 